\title{
CARACTERIZAÇÃO DE PROFESSORES E ESTUDANTES DE ENFERMAGEM EM JOÃO PESSOA - PARAÍBA
}

Francilene Jane Rodrigues Pereira ${ }^{1}$, Sérgio Ribeiro dos Santos ${ }^{2}$, César Cavalcanti da Silva ${ }^{3}$

Resumo: O objetivo do estudo é descrever o perfil socioeconômico de professores de Instituições de Ensino Superior em Enfermagem em João Pessoa-PB e quantificar, entre esses, portadores de necessidades especiais. Trata-se de um estudo exploratório descritivo quantitativo. Para a coleta dos dados utilizou-se um questionário estruturado. O programa SPSS para Windows foi utilizado na estatística descritiva. Participaram da pesquisa 264 estudantes e 25 professores, dos quais 49 estudantes e 6 professores apresentaram algum tipo de necessidade especial. Embora em pequena porcentagem nas instituições pesquisadas, ações são relevantes para fornecer aparato especial no sentido de suprir as necessidades dessa clientela.

PALAVRAS-CHAVE: Instituições de ensino superior; Enfermagem; Fatores Socioeconômicos.

\section{CHARACTERIZATION OF NURSING TEACHERS AND STUDENTS IN JOÃO PESSOA - PARAÍBA}

\begin{abstract}
The purpose of this study is to describe the socioeconomic profile of teachers in Institutions of Higher Education in Nursing in João Pessoa, and to quantify, among these, those with special needs. This is an exploratory descriptive and quantitative study. To collect data we used a structured questionnaire. SPSS for Windows was used for descriptive statistics. Study participants were 25 teachers and 264 students, of which 49 students and six teachers had some kind of special need. Although the low percentage in the research institution, actions are important to provide special apparatus in order to meet the needs of this clientele.
\end{abstract}

KEYWORDS: Institutions of higher education; Nursing; Socioeconomic Factors.

\section{CARACTERIZACIÓN DE PROFESORES Y ESTUDIANTES DE ENFERMERÍA EN JOÃO PESSOA - PARAÍBA}

RESUMEN: El objetivo del estudio fue describir el perfil socioeconómico de profesores de Instituciones de Enseñanza Superior en Enfermería en João Pessoa, Paraíba, y cuantificar, entre eses, portadores de necesidades especiales. Es un estudio exploratorio descriptivo cuantitativo. Para recoger los datos, fue utilizado un cuestionário estructurado. El programa SPS para Windows fue utilizado en la estadística descriptiva. Han participado de la investigación 264 estudiantes y 25 profesores, de los cuales 49 estudiantes y 6 profesores presentaron algún tipo de necesidad especial. Aunque en pequeña porcentaje en la institución investigada, acciones son relevantes para fornecer aparato especial en sentido de suplir las necesidades de esa clientela.

PALABRAS CLAVE: Instituciones de enseñanza superior; Enfermería; Factores Socioeconómicos.

${ }^{1}$ Enfermeira. Membro do Grupo de Estudo e Pesquisa em Administração e Informática em Saúde-GEPAIE da Universidade Federal da Paraíba-UFPB.

${ }^{2}$ Enfermeiro. Doutor em Sociologia. Professor Associado do Departamento de Enfermagem Clínica-UFPB. Líder do GEPAIE.

${ }^{3}$ Enfermeiro. Doutor em Enfermagem. Professor Associado do Departamento de Enfermagem Clínica-UFPB. Membro do GEPAIE.

Autor correspondente:

Francilene Jane Rodrigues Pereira

Universidade Federal da Paraíba

Av. Apolônio Nóbrega, 258 - 58050-260 - João Pessoa-PB, Brasil

Recebido: 22/10/09

E-mail: janeufpb@hotmail.com

Aprovado: 03/07/10

Cogitare Enferm. 2010 Jul/Set; 15(3):486-91 


\section{INTRODUÇÃO}

A defesa da cidadania e do direito à educação das pessoas com necessidades especiais se dá como uma reflexão muito recente em nossa sociedade. Destaca-se a falta de conhecimento sobre as necessidades especiais como um dos principais fatores para a marginalização e a ignorância a respeito das diferenças ${ }^{(1)}$.

Há 25 anos, o tema da atualidade em Educação Especial era a reflexão sobre as possibilidades e as metodologias de integração de alunos com necessidades educativas especiais na educação préprimária e primária ${ }^{(2)}$. Hoje, como consequência dos avanços verificados nos diferentes graus de ensino, procura-se refletir sobre a integração/inclusão de estudantes com necessidades especiais nas Universidades.

A partir dessa reflexão inicial, expomos o grande desafio enfrentado pelos deficientes nas Instituições de Ensino Superior (IES), professores e estudantes, envolvidos na construção do conhecimento e nas demandas impostas pela sociedade moderna e complexa, na tentativa de superar as dicotomias cada vez mais excludentes, em direção a uma formação profissional inclusiva, interativa e acolhedora. Portanto, ao falar de educação inclusiva, no contexto das IES, nos surgiu o seguinte questionamento: Qual o perfil socioeconômico do meio onde estão inseridos os portadores de necessidades especiais das IES no Município de João Pessoa/PB?

Nessa perspectiva, traçamos como objetivos: descrever o perfil socioeconômico de professores e estudantes em Instituições de Ensino Superior em Enfermagem em João Pessoa que possuem entre eles deficientes, bem como quantificar professores e estudantes que possuem algum tipo de necessidade especial.

\section{METODOLOGIA}

Trata-se de um estudo exploratório e descritivo com abordagem quantitativa realizada em três (IES) que ministram Curso de Graduação em Enfermagem no Município de João Pessoa, realizado no período de agosto de 2008 a junho de 2009. Participaram do estudo uma instituição pública (a ser denominada Pública) e duas privadas. Dentre as instituições privadas, uma exclusivamente de Enfermagem, e será neste estudo denominada IES Privada 1 , e outra que oferta vários outros cursos além do curso de Enfermagem, a ser denominada IES Privada 2. A escolha dessas instituições, dentre as 9 existentes na cidade, foi a permissão de suas respectivas gestões para realização da pesquisa em seu âmbito.

Os participantes do estudo constituíram-se de professores e estudantes de Enfermagem, portadores ou não de necessidades especiais, com os seguintes critérios de inclusão: [1] apresentar vínculo com a instituição; [2] estar presente no momento da coleta de dados e [3] aceitar participar da pesquisa.

A coleta de dados teve início após aprovação do projeto de pesquisa pelo Comitê de Ética, através do parecer n. 0050/2008. Aos participantes foram oferecidas as orientações relacionadas ao estudo quanto à finalidade da pesquisa. Mediante a leitura do Termo de Consentimento Livre e Esclarecido, conforme estabelece a Resolução n. 196/96 do CNS, que regulamenta pesquisa com seres humanos, foi ressaltada a garantia do sigilo, a participação voluntária, o não-prejuízo ao participar do estudo, e a possibilidade a qualquer momento de desistir do mesmo ${ }^{(3)}$.

Para obtenção dos dados foi utilizado um questionário estruturado, composto por dados socioeconômicos e o questionamento sobre a existência de alguma necessidade especial. Os dados foram apurados estatisticamente, através do software SPSS (Statistical Package for the Social Sciences) para desenvolver a estatística descritiva.

\section{RESULTADOS E DISCUSSÃO}

Os resultados se referem às condições socioeconômicas dos estudantes e professores das IES selecionadas e à identificação de necessidades especiais entre eles. A população apta a participar da pesquisa compunha-se inicialmente de 98 professores e 795 estudantes nas três instituições, porém, a amostragem não probabilística foi composta por 25 professores e 264 estudantes, devido ao desinteresse de muitos constituintes das instituições privadas em participar do estudo, refletindo o pequeno número e até a nãoparticipação de professores de uma das instituições privadas.

A tabela 1 mostra que a maioria dos professores participantes do estudo é da universidade pública, ou seja, $68 \%$, portanto com mais disponibilidade. Por outro lado, os professores das instituições privadas, geralmente, vão até as IES apenas para ministrar sua aula, mas não permanecem, o que torna mais difícil encontrá-los na instituição. 
Tabela 1 - Número e percentual de professores e estudantes de Enfermagem em Instituições de Ensino Superior. João Pessoa, 2009.

\begin{tabular}{lcccc}
\hline IES & \multicolumn{2}{c}{ Professores } & \multicolumn{2}{c}{ Estudantes } \\
& Número & \% & Número & \% \\
\hline Pública & 17 & 68,0 & 146 & 55,3 \\
Privada 1 & 00 & 00,0 & 20 & 11,0 \\
Privada 2 & 08 & 32,0 & 89 & 33,7 \\
Total & 25 & 100,0 & 264 & 100,0 \\
\hline
\end{tabular}

Ainda, conforme tabela 1 , percebe-se que a maioria dos estudantes, 55,3\%, pertencia à Pública. Essa situação pode ser justificada pela quantidade de instituições que ministram o curso de Enfermagem e as características de cada uma delas, diversificando a procura dos usuários por aquela que condiz com sua condição. A Pública é das IES que apresenta o mais antigo curso de Enfermagem, possuindo um grande quantitativo de alunos, situação oposta das outras duas instituições, que não concluíram nenhuma turma, a exemplo da IES Privada 2, que possui o menor quantitativo de alunos.

No que se refere à Pública, ainda deve ampliar o significado de sua função social e assegurar o direito à educação e à igualdade de oportunidades para aqueles que, tradicionalmente, não fazem parte de seu alunado, como é o caso das pessoas com necessidades especiais $^{(4)}$.

A relação dos estudantes com necessidades especiais e a Universidade é um processo interativo em que se devem considerar, conjuntamente, as suas características e as solicitações, recursos e possibilidades das Universidades. Esta relação encontra-se, no entanto, condicionada pelo reconhecimento de direitos da pessoa com necessidades especiais. Tradicionalmente, consideram-se três direitos "educacionais": a) o direito à educação - a Universidade faz parte do sistema educativo; b) o direito à igualdade de oportunidades, isto é, o direito de usufruir de oportunidades semelhantes às dos seus pares sem condições especiais e c) o direito à participação social - consubstanciado no direito de usufruir dos equipamentos e condições postos à disposição de toda a comunidade ${ }^{(2)}$.

A maioria dos estudantes (Tabela 2) ingressou no curso de Enfermagem no período de 2006 a 2007, e no ano de 2008, refletindo a abertura das universidades

Tabela 2 - Número e percentual do período de ingresso dos estudantes de Enfermagem em Instituições de Ensino Superior. João Pessoa, 2009.

\begin{tabular}{lcc}
\hline Ano & \multicolumn{2}{c}{ Estudantes } \\
& Número & \% \\
\hline 2002 e 2003 & 04 & 1,5 \\
2004 e 2005 & 51 & 19,3 \\
2006 e 2007 & 123 & 46,6 \\
2008 & 83 & 31,4 \\
Não informaram & 03 & 1,2 \\
Total & 264 & 100,0 \\
\hline
\end{tabular}

privadas nesses últimos anos e aumentando o número de alunos ingressantes.

No âmbito educacional, no primeiro mandato do então Presidente da República, Fernando Henrique Cardoso, um dos focos foi nas Leis de Diretrizes e Bases da Educação (LDB), de 1996. Este conjunto de leis propiciou a expansão do ensino superior privado, e trouxe, entre outras recomendações, a organização de um modelo pedagógico capaz de adaptar-se à dinâmica das demandas da sociedade, proporcionando uma carga horária mínima que permitisse a flexibilização do tempo de duração do curso, de acordo com a disponibilidade e esforço do aluno. Porém, segundo o entendimento dos "empresários da educação", ele representou liberalidade para a criação de novos cursos e formatação dos "tradicionais" (dentre eles, o curso de Enfermagem). Este fato retirou a educação da esfera dos chamados direitos da cidadania e a colocou como um serviço disponível no mercado, devendo ser comprada pelos interessados ${ }^{(5)}$.

É importante lembrar que na Paraíba, atualmente, existem dezesseis faculdades que ministram o curso de Enfermagem, dentre as quais, apenas três delas são de ensino público. Em João Pessoa, estão localizadas nove dessas instituições de ensino, sendo apenas uma delas pública.

O tempo de atuação dos professores nas IES (IES) é diversificado, porém $60 \%$ estão atuando há menos de 10 anos; $28 \%$ dos professores têm entre 10 a 20 anos de ensino na instituição. Por outro lado, a

Tabela 3 - Número e percentual do tempo de atuação dos professores de Enfermagem em Instituições de Ensino Superior. João Pessoa, 2009.

\begin{tabular}{lcc}
\hline Ano & \multicolumn{2}{c}{ Professores } \\
& Número & \% \\
\hline Menos de 10 & 15 & 60,0 \\
10 a 20 & 07 & 28,0 \\
21 a 30 & 02 & 8,0 \\
Mais de 31 & 01 & 4,0 \\
Total & 25 & 100,0 \\
\hline
\end{tabular}


abertura das faculdades privadas nos últimos anos tem possibilitado oportunidade aos professores em início de carreira.

A tabela 4 revela que os professores de Enfermagem são, em sua maioria, do sexo feminino (84\%), retratando a dinâmica do processo de gênero, em que mais graduandos do sexo feminino concluem o curso, maior a probabilidade de esses alunos serem professores. Também entre os estudantes prevalece uma maioria de sexo feminino $(90,2 \%)$, o que é justificável pelo fato do curso de Enfermagem possuir características históricas que se reproduzem atraindo mais estudantes do sexo feminino.

Tabela 4 - Número e percentual dos estudantes e professores de Enfermagem em Instituições de Ensino Superior, segundo o gênero e faixa de idade. João Pessoa, 2009.

\begin{tabular}{lcccc}
\hline Variáveis & \multicolumn{2}{c}{ Professores } & \multicolumn{2}{c}{ Estudantes } \\
& Número & \% & Número & \% \\
\hline Gênero & & & & \\
Masculino & 04 & 16,0 & 26 & 9,8 \\
Feminino & 21 & 84,0 & 238 & 90,2 \\
Faixa de idade & & & & \\
Menos de 20 anos & - & - & 56 & 21,3 \\
De 20 a 30 anos & 02 & 8,0 & 194 & 73,6 \\
De 31 a 40 anos & 07 & 28,0 & 11 & 3,9 \\
De 41 a 50 anos & 10 & 40,0 & 02 & 0,8 \\
Acima de 50 anos & 05 & 20,0 & 01 & 0,4 \\
Não informaram & 01 & 4,0 & - & - \\
\hline
\end{tabular}

O fato da pesquisa ter sido realizada em escolas de Enfermagem justifica a presença do sexo feminino, como nos mostra um estudo realizado sobre o perfil dos estudantes das Escolas de Enfermagem de Minas Gerais, que pode ser comparado com outros Estados brasileiros, revelando que a grande maioria $(88 \%)$ dos estudantes amostrados é do sexo feminino(6).

A idade que apresenta maior frequência entre os professores é entre 41 a 50 anos, representando $40 \%$ e, em seguida, dos 31 a 40 anos, com $28 \%$. Esse perfil caracteriza maturidade da amostra.

Por outro lado, a idade dos estudantes revela que as universidades possuem, em sua maioria, jovens na faixa etária entre 20 e 30 anos, ou seja, época da idade adulta onde muitos buscam encontrar sua identidade profissional, a fim de ingressar no concorrido mercado de trabalho. A faixa etária dos estudantes menores de 20 anos também se fez presente, revelando que a inserção no curso superior acontece cedo, o que expressa a busca de uma carreira profissional.

Como se observa na tabela 5 , quanto ao estado civil dos professores, $68 \%$ afirmam ser casados. Isso se explica pelo fato de que o indivíduo, ao ganhar estabilidade financeira, procura o equilíbrio social e emocional, através da constituição de um vínculo familiar. Assim, 68\% revelaram possuir filhos e, na sua maioria, dois filhos.

Tabela 5 - Caracterização social de estudantes e professores de Enfermagem em Instituições de Ensino Superior. João Pessoa, 2009.

\begin{tabular}{lcccc}
\hline Variáveis & \multicolumn{2}{c}{ Professores } & \multicolumn{2}{c}{ Estudantes } \\
& Número & \% & Número & \% \\
\hline Estado Civil & & & & \\
Solteiro & 04 & 16,0 & 231 & 87,5 \\
Casado & 17 & 68,0 & 25 & 9,5 \\
Viúvo & 02 & 8,0 & 01 & 0,4 \\
Divorciado & 01 & 4,0 & 02 & 0,8 \\
União estável & 01 & 4,0 & 05 & 1,9 \\
№ de filhos & & & & \\
Sem filhos & 08 & 32,0 & 234 & 88,6 \\
1 & 04 & 16,0 & 20 & 7,6 \\
2 & 09 & 36,0 & 08 & 3,0 \\
3 & 03 & 12,0 & 01 & 0,4 \\
$>3$ & 01 & 4,0 & 01 & 0,4 \\
№ de pessoas no & & & & \\
núcleo familiar & & & & \\
$1-3$ & 10 & 40,0 & 68 & 25,7 \\
$4-6$ & 13 & 52,0 & 178 & 67,4 \\
$7-9$ & 01 & 4,0 & 12 & 4,6 \\
$>9$ & - & - & 04 & 1,6 \\
Não informaram & 01 & 4,0 & 02 & 0,8 \\
\hline
\end{tabular}

Em relação aos estudantes, 87,5\% são solteiros; isso reflete o quanto estão ocupados com a formação profissional, adiando assim um relacionamento afetivo mais sério. Deles, apenas 9,5\% e 1,9\% são casados ou vivem numa união estável, respectivamente.

Esses resultados vêm confirmar outros estudos que mostram que, nas Escolas onde se ministram o curso de Enfermagem, há predominância de solteiros $(80 \%)$, entre os estudantes. A presença de filhos também é pouca, pois $88,7 \%$ dos entrevistados não possuem filhos ${ }^{(6)}$.

Por outro lado, o núcleo familiar dos estudantes é composto de famílias com 4 a 6 pessoas (67,4\%), seguidos de 1 a 3 pessoas $(25,7 \%)$, o que vem corroborar o fato da família moderna ser constituída de poucos filhos.

A renda familiar dos professores, conforme a tabela 06 , está acima de 7 salários mínimos (88\%). 
Além disso, a participação na renda familiar é bastante significativa, pois a maioria contribui com mais de 7 salários mínimos (48\%).

A renda das famílias dos estudantes é variável. Verifica-se que $31,3 \%$ possuem renda de 1 a 4 salários mínimos e 24,7\% com renda de 5 a 7 salários mínimos. Constatou-se, ainda, que os estudantes muito pouco contribuem com a renda familiar. Isso se explica pelo fato deles estudarem na maior parte de seu tempo. Além disso, os cursos da área de saúde, em geral, são diurnos, dificultando a possibilidade de ter emprego. Porém, existem aqueles que contribuem com certa quantia, proveniente de alguma atividade ou mesmo de bolsas disponibilizadas pela universidade.

Tabela 6 - Condição econômica dos estudantes e professores de Enfermagem das Instituições de Ensino Superior. João Pessoa, 2009.

\begin{tabular}{lcccc}
\hline Variáveis & \multicolumn{3}{c}{ Professores } & \multicolumn{3}{c}{ Estudantes } \\
& Número & \% & Número & \% \\
\hline Renda familiar & & & & \\
(em salário mínimo) & & & & \\
$<1$ & - & - & 06 & 2,3 \\
1 - 4 & - & - & 82 & 31,3 \\
5 -a 7 & 02 & 8,0 & 65 & 24,7 \\
$>7$ & 22 & 88,0 & 67 & 25,0 \\
Não informaram & 01 & 4,0 & 44 & 16,7 \\
Participação na & & & & \\
renda familiar & & & & \\
(em salário mínimo) & & & & \\
Nenhuma & - & - & 204 & 77,3 \\
$<1$ & - & - & 14 & 5,3 \\
1 - 4 & 02 & 8,0 & 18 & 7,1 \\
5 - 7 & 06 & 24,0 & 04 & 1,6 \\
$>7$ & 12 & 48,0 & - & - \\
Não informaram & 05 & 20,0 & 24 & 9,1 \\
\hline
\end{tabular}

Esses dados levam à reflexão sobre a importância de políticas públicas que de fato promovam a inserção do jovem no mercado de trabalho. Nesse sentido, a Declaração Universal dos Direitos Humanos, de 1948, constitui-se num dos primeiros passos nesta direção, possibilitando a todo cidadão o direito ao trabalho e à remuneração que lhe assegurem uma existência com dignidade humana ${ }^{(7)}$.

Quanto à procedência dos universitários, são poucos aqueles provenientes de escola pública, conforme a tabela 7 , sendo apenas $27,2 \%$, enquanto que a maioria (70,5\%) é de escola privada. Esse dado revela o quanto está precário o ensino fundamental e médio das escolas públicas, dificultando o ingresso desses alunos numa universidade.
Tabela 7 - Procedência dos estudantes de Enfermagem em Instituições de Ensino Superior quanto à instituição de ensino médio. João Pessoa, 2009.

\begin{tabular}{lcc}
\hline Procedência & \multicolumn{2}{c}{ Estudantes } \\
& Número & \% \\
\hline Não informaram & 06 & 2,3 \\
Escola Privada & 186 & 70,5 \\
Escola Pública & 72 & 27,2 \\
Total & 264 & 100,0 \\
\hline
\end{tabular}

Os dados da tabela 8 mostram que a totalidade dos professores e $97 \%$ dos estudantes possuem acesso a computador. Essa ferramenta é extremamente útil e demonstra o avanço da sociedade moderna e globalizada, em que os meios eletrônicos são essenciais no desenvolvimento das suas funções.

Tabela 8 - Número e percentual de professores e estudantes das IES com acesso ao computador. João Pessoa, 2009.

\begin{tabular}{lcccc}
\hline \multirow{2}{*}{$\begin{array}{l}\text { Acesso ao } \\
\text { computador }\end{array}$} & \multicolumn{2}{c}{ Professores } & \multicolumn{2}{c}{ Estudantes } \\
Número & $\mathbf{\%}$ & Número & $\mathbf{\%}$ \\
\hline Não informou & - & - & 01 & 0,4 \\
Não & - & - & 07 & 2,6 \\
Sim & 25 & 100,0 & 256 & 97,0 \\
Total & 25 & 100,0 & 264 & 100,0 \\
\hline
\end{tabular}

Em relação à condição de ser portador de necessidade especial (Tabela 9), observamos que 76\% dos professores e $81 \%$ dos estudantes se auto-referiram como não-portadores de necessidade especial; e $24 \%$ dos professores e $18,6 \%$ dos estudantes referiram ser portadores.

Tabela 9 - Distribuição das respostas de professores e estudantes de Enfermagem das Instituições de Ensino Superior, segundo a condição de ser portador de necessidade especial. João Pessoa, 2009.

\begin{tabular}{lcccc}
\hline PNE & \multicolumn{2}{c}{ Professores } & \multicolumn{2}{c}{ Estudantes } \\
& Número & $\mathbf{\%}$ & Número & \% \\
\hline Não informou & - & - & 01 & 0,4 \\
Não & 19 & 76,0 & 214 & 81,0 \\
Sim & 06 & 24,0 & 49 & 18,6 \\
Total & 25 & 100,0 & 264 & 100,0 \\
\hline
\end{tabular}

Quanto à caracterização da necessidade especial, seis professores e 46 estudantes revelaram possuir deficiência visual parcial. Ainda, dois estudantes revelaram possuir necessidade especial física e um, auditiva. 
Nesta pesquisa, a necessidade visual foi caracterizada pela incapacidade ou dificuldade permanente de enxergar; necessidade física abrange as paralisias permanentes ou totais de um ou ambos os membros e/ou falta parcial ou total de membros; e necessidade auditiva foi considerada como a incapacidade ou grande dificuldade de ouvir ${ }^{(8)}$.

No Nordeste brasileiro, $16,8 \%$ da população possuem necessidades especiais. Em função da pobreza explícita e da falta de políticas públicas voltadas para educação educação inclusiva nesta região, a exclusão social é relevante. O Estado do Ceará apresenta 17,34\% da população como portadores de necessidades especiais ${ }^{(9)}$.

O cuidado à saúde de portadores de necessidades especiais demanda incluir a educação a fim de incluí-los como autores de sua história ${ }^{(10)}$.

\section{CONSIDERAÇÕES FINAIS}

Embora em pequena porcentagem dentro das Instituições de Ensino Superior, os portadores de necessidades especiais se fazem presentes e suas características devem ser avaliadas para oferecer o suporte necessário.

Esse estudo visa contribuir para a visualização objetiva das pessoas com necessidade especiais em algumas IES em João Pessoa e das condições socioeconômicas manifestadas por estas. Salienta-se a importância de gerar práticas inclusivas, contribuindo para o desenvolvimento destas pessoas no âmbito universitário.

\section{REFERÊNCIAS}

1. Pacheco RV, Costa FAT. O processo de inclusão de acadêmicos com necessidades educacionais especiais na Universidade Federal de Santa Maria. Rev Centro Educ: Educ Espec [Internet].2006;(27) [acesso em 15 set 2008]. Disponível: http://tiny.cc/zdndh

2. Rodrigres D. A inclusão na universidade: limites e possibilidades da construção de uma universidade inclusiva. Rev Centro Educ: Educ Espec [Internet]. 2004;(23) [acesso em 05 set 2008]. Disponível: http:// tiny.cc/6nn 44

3. Ministério da Saúde (BR). Conselho Nacional de Saúde. Resolução n. 196, de 10 de outubro de 1996, Brasília; Diretrizes e normas regulamentadoras de pesquisa envolvendo seres humanos. Brasília, 1997.
4. Moreira LC, Baumel RCRC. Currículo em educação especial: tendência e debate. Educar. 2001; (17):125-37.

5. Barbosa TSC, Baptista SS. Movimento de expansão dos cursos superiores de enfermagem na região centrooeste do Brasil: uma perspectiva histórica. Rev Eletron Enferm [Internet]. 2008;10(4) [acesso em 5 jan 2009]. Disponível: http://tiny.cc/8pkm1

6. Nakamae DD, Araújo MRN, Carneiro MLM, Vieira LJ, Coelho S. Caracterização socioeconômica e educacional do estudante de enfermagem nas escolas de Minas Gerais. Rev Esc Enferm USP. 1997;31(1):109-18.

7. Declaração Universal dos Direitos Humanos. Adotada e proclamada pela resolução 217 A (III) da Assembléia Geral da Organização das Nações Unidas, de 10 de dezembro de 1948: Art. 23.

8. Carneiro AJCC. Pessoas com deficiência: dados para ampliar a inclusão. Col Est Cariocas. [Internet] 2005;5(2) [acesso em 23 set 2008]. Disponível: http:// tiny.cc/sbvgk

9. Freitas LPT, Oliveira LJ, Freitas JDB. Conhecendo os portadores de necessidades especiais do Município de Iguatu-Ceará. In: II Congresso de Pesquisa e Inovação da Rede Norte Nordeste de Educação Tecnológica; 2007 nov 27-30 [Internet] [acesso em 5 jan 2009]; João Pessoa-PB: 2007. Disponível: http://tiny.cc/63g3k

10. Milbrath VM, Soares DC, Cecagno D, Amestoy SC, Siqueira $\mathrm{HCH}$. Inserção social da criança portadora de necessidades especiais: a perspectiva materna. Cogitare Enferm. 2009;14(2):311-7. 